\title{
Determinant of successful implementation of Computerized Provider Order Entry (CPOE) system from physicians' perspective: Feasibility study prior to implementation
}

\author{
Parasto Amiri ${ }^{1}$, Bahlol Rahimi ${ }^{2}$, Hamid Reza Khalkhali ${ }^{3,4}$
}

${ }^{1}$ M.Sc. Student of Medical Informatics, Student Research Committee, Urmia University of Medical Sciences, Urmia, Iran

${ }^{2}$ Ph.D. of Medical Informatics, Associate Professor, Department of Health Information Technology, School of Allied Medical Sciences, Urmia University of Medical Sciences, Urmia, Iran

${ }^{3}$ Ph.D. of Biostatistics, Associate Professor, Department of Biostatistics and Epidemiology, School of Medicine, Urmia University of Medical Sciences, Urmia, Iran

${ }^{4} \mathrm{Ph} . \mathrm{D}$. of Biostatistics, Associate Professor, Patient Safety Research Center ,Urmia University of Medical Sciences, Urmia, Iran

\section{Type of article: Original}

\begin{abstract}
Background: Health information technology is a solution for medical error reduction through the implementation of Computerized Provider Order Entry (CPOE).

Objective: The aim of this study was to determine physicians' attitudes toward the implementation of CPOE.

Methods: This cross-sectional study was started in March 2017 and completed in June 2017. The study used a questionnaire to collect data from physicians in hospitals affiliated to Urmia University of Medical Sciences. We invited 200 physicians who were not using a CPOE system. Questionnaires were randomly distributed among physicians. In order to understand the physicians' attitude about implementation the CPOE system, we used the Diffusion of Innovation Theory, developed by E.M. Rogers. Data were analyzed by SPSS version 16.0, using descriptive statistics and one-way ANOVA. A $p$ value $<0.05$ was considered to be statistically significant.

Results: Most of the physicians were women $(\mathrm{n}=54,60 \%)$ and the average age of the physicians was $36.39 \pm 8.42$ years. About three-quarters of the physicians $(76.66 \%)$ reported that they found the CPOE system adapted to their specific professional practice. The relative advantage of the CPOE system was estimated to be $42.22 \%$ for physicians and the complexity of that was $13.33 \%$. There was no significant relationship between Compatibility, Relative advantages and Complexity with physicians' experience in HIS use and physicians' degree of education ( $\mathrm{p}>0.05)$.

Conclusion: Since the role of CPOE systems is very important in hospitals in order to reduce medication errors and to improve the quality of care, our results can be used to assist the planning and introduction of CPOE systems.

Keywords: Medical order entry system, Attitude of health personnel, Patient safety, Diffusion of innovation, Feasibility studies
\end{abstract}

\section{Introduction}

Manual order entry may lead to errors and adverse drug events (ADEs) (1). Computerized physician order entry (CPOE) systems have been recommended by the Leapfrog Group to decrease errors and ADEs in the USA (2). CPOE systems are computer applications that allow a physician to use a computer to directly enter electronic orders such as medications, laboratory, radiology, referral and procedures (3) that can be an effective approach to improve

\section{Corresponding author:}

Associate Professor Dr. Bahlol Rahimi, Department of Health Information Technology, School of Allied Medical Sciences, Urmia University of Medical Sciences, Urmia, Iran.

Tel: +98.4432752305, Fax: +98.4432770047, Cell phone: +98.9128128119, Email: bahlol.rahimi@gmail.com

Received: July 22, 2017, Accepted: October 26, 2017, Published: January 2018

iThenticate screening: October 03, 2017, English editing: December 28, 2017, Quality control: January 04, 2018

This article has been reviewed / commented by four experts

(C) 2018 The Authors. This is an open access article under the terms of the Creative Commons Attribution-NonCommercialNoDerivs License, which permits use and distribution in any medium, provided the original work is properly cited, the use is non-commercial and no modifications or adaptations are made. 
patient safety and physician performance (4-17). Del Beccaro et al., in their study, showed that after implementation of CPOE, the mortality rate decreased from $4.2 \%$ to $3.46 \%$ (18). Several studies demonstrated that using CPOE reduces medication-related errors $(15,17,19-21)$. At LDS Hospital, the use of CPOE for anti-infective agents reduced adverse drug events and improved the use of agents that were appropriate to the infecting organism (22). Many statistics show that about $15 \%$ of hospitals in the United States are using CPOE, while in many of these hospitals in which a CPOE has been implemented, few physicians use the system $(23,24)$. Several governmental and non-governmental agencies have made efforts to encourage CPOE use (25-27). For example, the Leapfrog Group stated that $4.1 \%$ of the reporting hospitals in their recent survey had CPOE fully implemented, but few hospitals now use CPOE (28). In other studies, it has been shown that CPOE systems are highly valuable tools to have for enhanced efficiency and effectiveness in the health setting (15). In 2012, almost 70 percent of hospitals used computerized ordering for medications, labs, and radiology tests (29). Khajoui et al. identified nine CPOEspecific design aspects that influence the ease of use, efficiency, workflow, and medication safety (30). The related studies performed in Iran have demonstrated that a high frequency of medication errors and ADEs are significant problems for the Iranian healthcare system $(31,32)$. Kazemi et al. reported that although there are different barriers confronting the implementation and continuation of CPOE in Iranian hospitals, physicians have a willingness to use them if these systems provide significant benefits including high reliability, educational use and reduced human errors (33). Feasibility studies have much impact on projects' destination. Many of the problems that occur in the implementation and adoption of systems' phases are due to shortcomings in primary studies. One of the studies needed to be performed in the feasibility studies phase is to take stakeholders' opinions. To determine physicians' attitudes, as one of the important stakeholders, toward the necessity of systems they are going to use in the future, then employ their opinion in pre-design and pre-implementation of CPOE, may prevent or decrease the failure in CPOE's project as well as the decision makers' plans and expectations. The aim of this study was therefore to determine factors that may influence CPOE adoption among physicians in hospitals affiliated to Urmia University of Medical Sciences in 2017.

\section{Material and Methods}

West Azerbaijan is a province in the north west of Iran. Urmia is the largest city in West Azerbaijan province, with 667,499 inhabitants. Emam Khomeini, Motahari, Seyedoshohada and Taleghani are hospitals affiliated to Urmia University of Medical Sciences that are using the Hospital Information System (HIS). This Cross-sectional study was started in March 2017 and completed in June 2017. One questionnaire was distributed to physicians who worked in hospitals affiliated to Urmia University of Medical Sciences. The study population consisted of all physicians in hospitals affiliated to Urmia University of Medical Sciences. A total of 200 questionnaires were randomly distributed among physicians and the number of completed returned questionnaires was 90 from all physicians (overall response, 45\%). The questionnaire was in Farsi language and contained 60 questions and was in five-point Likert scale format. We used an adapted questionnaire (34) to evaluate the attitudes of physicians for implementation of the CPOE system. The questionnaire was divided into six main sections: 12 questions about participants' demographic information, 7 questions about determining the level of computer literacy physicians, 4 questions about determining the level of CPOE literacy physicians, 21 questions about determining the attitude of physicians about the effectiveness of CPOE, 8 questions about determining the attitude of physicians of the complexity arising from the implementation of CPOE, and 8 questions about determining the attitude of physicians regarding the technology necessary for the implementation of CPOE. Face validity of the questionnaire was assessed by gathering 4 professionals' opinions with backgrounds in medical informatics, health information management, and statistics. For reliability of this questionnaire, we tested it with 15 physicians and asked them to put comments on the questionnaire. The questionnaire was revised according to their feedback. The reliability was confirmed by calculating the internal correlation coefficient $(\alpha=0.78)$. Data analysis was performed using SPSS version 16.0 (SPSS Inc., Chicago, Illinois, USA). To analyze data, mean values and standard deviations were calculated. The differences in the attitudinal scores between groups were tested by one-way ANOVA. A p value of $<0.05$ was considered to be statistically significant.

\section{Results}

As shown in Table 1, characteristics of the responding physicians, a total of 200 questionnaires were distributed among the study physicians, and the response rate was $45 \%(\mathrm{n}=90)$. Most of the physicians were women $(\mathrm{n}=54$, $60 \%$ ) and the average age of the physicians was $36.39 \pm 8.42$ years. The average work experience for physicians was $11 \pm 8.62$ years, respectively (Table 1). In this study, the highest proportion of the respondents were interns with 52 (57.77\%), while the lowest proportion of the respondents were junior specialist physicians with $5(5.55 \%)$, as shown in Table 1. In this study, we found that the received relative advantages of the system was $76.66 \%$ for the 
respondents. The physicians found compatibility of the CPOE was $42.22 \%$ and complexity to use was $13.33 \%$ (Table 2). The results showed that the relative advantages $(60.99 \pm 11.96)$ and compatibility (30.36 \pm 4.74$)$ among male physicians were higher than that of the females (Table 3). There was no significant relationship between Compatibility, Relative advantages and Complexity with gender of physicians ( $p>0.05)$. Young physicians also accepted CPOE implementation more easily (Table 3). There was no significant relationship between Compatibility, Relative advantages and Complexity with age of physicians ( $>0.05)$. The results showed that degree of education has the same effect on the recognition of Relative advantages, Compatibility and Complexity of the CPOE system. There was no meaningful relationship between Compatibility, Relative advantages and Complexity with degree of education $(\mathrm{p}>0.05)$. Also, results indicated that experience using the HIS has no relation with the recognition of Relative advantages, Compatibility and Complexity of the CPOE system, there was no significant relationship between Compatibility, Relative advantages and Complexity with experience in HIS use ( $p>0.05)$. Generally, the level of physicians' computer literacy was $16.67 \%(\mathrm{n}=15)$. Respondents indicated that they had experience with the HIS system (61.2\%). Collected data showed that $24.44 \%$ of physicians were aware of the CPOE system. Our findings show that half of the physicians used computers to facilitate daily tasks, to read books, and to download scientific content from the internet, also to work on the PC while at work. The results showed that physicians have diverse ideas about the relative advantages of the CPOE system on work efficiency and patient safety (compatibility section from Table 2). Our findings show that $32.22 \%$ of the physicians agreed that the system is faster to handle than the paper-based system. However, $45.55 \%$ of the respondents agreed that the system may increase the legibility of prescriptions. An up percentage of the physicians (84.44\%) agreed that the system will save time for staff. Although $66.67 \%$ of the physicians agreed that the system reduces the risk of medication error and that the system helps to achieve a high level of patient safety $(78.89 \%)$, nevertheless, $42.22 \%$ of the physicians agreed that the system will be more effective than the paper-based system. The respondents offered diverse opinions about the relative advantages of the CPOE system on work compatible with physicians' values and needs (advantages section from Table 2). An up percentage of the physicians (76.67\%) agreed that the paper-based system is more compatible than the CPOE system. About half of the physicians (52.22\%) agreed that the CPOE system will increase computer dependency. In addition, $37.8 \%$ of the respondents agreed that the system may lead to software and hardware problems, which will impact on time use. A low percentage of the physicians (15.6\%) agreed that the system will raise doubts about completeness and reliability of data (complexity section from Table 2). Notably, only $8.89 \%$ of the physicians agreed that the system introduction will lead to more adverse drug events. Findings show that $22.22 \%$ of the physicians agreed that providing much information may lead to confusion in clinical decisions doctor. The results revealed that $55.56 \%$ of the physicians agreed that the system may cause some non-human errors. However, $41.11 \%$ of the physicians agreed that the system will lead to rework (recorded on paper and registration system). The respondents reported that $22.22 \%$ of the physicians agreed that the system will not be secure, because unauthorized people would have access to confidential patient records.

Table 1. Characteristics of the physicians in the final study population

\begin{tabular}{|l|l|l|l|}
\hline Characteristic & Male & $\%$ \\
\hline Sex & Female & 36 & 40 \\
\hline Age groups (years) & $20-29$ & 54 & 60 \\
\cline { 2 - 4 } & $30-39$ & 24 & 26.67 \\
\cline { 2 - 4 } & $40-49$ & 32 & 35.56 \\
\cline { 2 - 4 } & $50-59$ & 20 & 22.22 \\
\hline \multirow{5}{*}{ Experience Using the system HIS (months) } & NO & 14 & 15.56 \\
\cline { 2 - 4 } & $<1$ & 35 & 38.89 \\
\cline { 2 - 4 } & $2-6$ & 14 & 15.55 \\
\cline { 2 - 4 } & $6-12$ & 14 & 15.55 \\
\cline { 2 - 4 } & $>12$ & 7 & 7.78 \\
\hline Training level & Interns & 20 & 22.22 \\
\cline { 2 - 4 } & Residents & 52 & 57.77 \\
\cline { 2 - 4 } & Junior specialist & 5 & 17.88 \\
\cline { 2 - 4 } & Senior consultant & 10 & 11.11 \\
\cline { 2 - 4 } & General practitioners & 9 & 10 \\
\hline
\end{tabular}


Table 2. Distribution of respondents' agreement with statements about Compatible, Advantages and Complexity of the CPOE system

\begin{tabular}{|c|c|c|c|}
\hline \multicolumn{2}{|l|}{ Questions } & $\mathrm{n}$ & $\%$ \\
\hline \multirow[t]{9}{*}{ Compatibility } & CPOE allows more efficient decision-making when you want to prescribe drugs & 75 & 83.3 \\
\hline & CPOE makes it possible to correct errors in prescriptions & 56 & 62.2 \\
\hline & CPOE provides clinical decision-making support when the physician wants to prescribe medicines & 72 & 80 \\
\hline & CPOE increases the reliability of data & 75 & 83.3 \\
\hline & CPOE contributes to information exchange between different caregivers & 74 & 82.2 \\
\hline & CPOE helps document patient-care processes & 76 & 84.4 \\
\hline & CPOE reduces the psychological effects due to the lack of information on patients' records & 77 & 75.5 \\
\hline & CPOE provides drug doses according to patient characteristics & 53 & 58.9 \\
\hline & CPOE enhances coordination of pharmacies with clinical departments & 82 & 91.1 \\
\hline \multirow{12}{*}{$\begin{array}{l}\text { Relative } \\
\text { advantages }\end{array}$} & CPOE is easier to manage than paper records & 71 & 78.9 \\
\hline & The paper record is lower than CPOE for handling prescriptions & 61 & 67.7 \\
\hline & CPOE saves time for staff & 76 & 84.5 \\
\hline & CPOE reduces the risk of prescription error & 60 & 66.6 \\
\hline & $\begin{array}{l}\text { CPOE provides an opportunity for effective communication with other staff in the treatment of the } \\
\text { patient }\end{array}$ & 67 & 74.4 \\
\hline & CPOE decreases the number of staffing & 42 & 53.3 \\
\hline & CPOE increases patients' satisfaction & 88 & 97.8 \\
\hline & CPOE leads to profitability for the hospital & 34 & 37.8 \\
\hline & CPOE helps to achieve a high level of patient safety & 71 & 78.9 \\
\hline & CPOE increases the legibility of the data & 41 & 45.6 \\
\hline & CPOE is a better approach than paper for prescribing & 84 & 93.3 \\
\hline & CPOE decreases the repetitive actions & 35 & 38.9 \\
\hline \multirow[t]{8}{*}{ Complexity } & CPOE causes doubts about reliability/completeness of data & 14 & 15.6 \\
\hline & CPOE provides much information leading to physicians' confusion in decision-making & 20 & 22.2 \\
\hline & CPOE leads to non-human errors & 50 & 55.6 \\
\hline & CPOE contributes to / requires double documentation (on paper and in the CPOE) & 37 & 41.1 \\
\hline & CPOE leads to computer-related problems (software and hardware) & 34 & 37.8 \\
\hline & CPOE increases computer dependency & 47 & 52.2 \\
\hline & CPOE leads to more adverse drug events & 8 & 8.9 \\
\hline & CPOE leads to unauthorized access to confidential patient records & 20 & 22.2 \\
\hline
\end{tabular}

Table 3. Proportion of the respondents who agreed with statements regarding the system's compatibility, relative advantages, and complexity of use

\begin{tabular}{|l|l|l|l|l|l|}
\hline \multirow{2}{*}{ Attributions of the diffusion of innovation theory } & \multicolumn{4}{l|}{ Gender; Mean \pm SD } & \multicolumn{2}{l|}{ Age (year); Mean \pm SD } \\
\cline { 2 - 6 } & Men & Women & $22-32$ & $33-42$ & $>43$ \\
\hline Relative advantages & $60.99 \pm 4.96$ & $49.66 \pm 4.64$ & $60.10 \pm 4.77$ & $44.66 \pm 4.64$ & $40.68 \pm 4.08$ \\
\hline Compatibility & $30.36 \pm 4.74$ & $24.97 \pm 4.78$ & $30.54 \pm 4.68$ & $24.97 \pm 4.78$ & $23.97 \pm 5.11$ \\
\hline Complexity & $21.20 \pm 4.25$ & $21.67 \pm 4.6$ & $19.15 \pm 4.48$ & $21.67 \pm 4.6$ & $17.13 \pm 4.58$ \\
\hline
\end{tabular}

\section{Discussion}

Characteristics of Rogers's diffusion of innovation (relative advantage, compatibility, complexity) guided this study. Our study analyzed physicians' attitudes about the CPOE system at four university hospitals. More than threequarters of physicians agreed that the CPOE system would adapt to their specific professional practice. Physicians receive relative intermediate advantage and less complexity from having the CPOE system. Since doctors are the main users of the CPOE system, this high compatibility and low complexity shows that physicians will support CPOE implementation and its utilization. Therefore, CPOE training workshops should be held in hospitals. With the fact that half of the doctors work with computers every day, online education can also be effective. Khajouei et al. and Ehteshami et al. indicated that knowledge of physicians, nurses and pharmacy personnel about CPOE was relatively high, but that is not consistent with our results $(30,35)$. To increase the likelihood of success in CPOE implementation, organizations should consider user training as critical success factors for CPOE projects. Our results show that physicians have little knowledge about CPOE. Based on the analysis conducted in the previous section, it is clear that physicians agreed that the CPOE system increased prescription legibility. In this case, the 
problem of reading handwritten notes would be eliminated and confidentiality would be preserved. In this regard, our results are consistent with the Kaushal et al. study (17). Our results show that most physicians agreed that the CPOE system reduces the risk of prescription error and helps to improve the patient's safety. Our findings show that CPOE with CDSS helps the doctor in decision-making and reduces drug interactions. CPOE is a significant technology to enhance patient safety. Patient safety is one of the most important advantages of CPOE systems and most physicians agreed in this context. The studies of Radley et al (36) and Reckmann et al. (37), demonstrated that CPOE can reduce prescription errors. Likewise, Leung et al. (38) demonstrated that using a CPOE, reduced 33.5\% of the drug side/adverse effects. Also, Riedmann et al., found that CPOE can reduce medication errors and adverse drug effects (39). Our findings show that physicians disagreed that the CPOE system leads to computer-related problems (both hardware and software). One of the most important findings in this study was that physicians disagreed that the CPOE system leads to adverse drug events, because of possibility of CPOE in correcting errors in prescriptions. In summary, we found that a majority of physicians agreed that the CPOE system increased computer dependency and led to non-human errors. Our results are consistent with previous studies $(40,41)$. From this perspective, the system users had no doubts regarding the reliability and completeness of the support provided by the system. This study had several limitations including the small sample size used in the survey. Secondly, our targeted population for this study was only physicians and no other health professionals. Thirdly, the response rate was only $45 \%$. A final limitation is that in this study, only quantitative analyses were performed.

\section{Conclusions}

Although, in the present study, the experience of doctors with the HIS system was high, they were not aware of CPOE. An up percentage of the physicians found that CPOE is beneficial and implementation in most hospitals is necessary after reading a one-page introduction of CPOE. The CPOE system reduces medication error, ADEs, and helps to achieve a high level of patient safety, and this will lead hospitals to their missions and their strategic goals, inevitably improving quality of care. The successful implementation of the CPOE is not possible if its requirements have already been discovered, and positive attitudes of their stockholders, mainly physicians, towards CPOE is acquiesced. Therefore, we suggest that having training courses before implementing CPOE is very necessary and vital. Also, for the success of CPOE, the procurement and installation of hardware and software is required. We recommend that complementary studies should be done on other stockholders such as nurses and paramedical staff with the same methodology, to determine their opinions about the CPOE benefits or hindrences in their daily work and patient safety.

\section{Acknowledgments:}

This study was supported by Urmia University of Medical Sciences, Urmia, Iran (grant number 1394-01-42-2106). The authors wish to thank all the physicians who participated in this study. All authors read and approved the final manuscript.

\section{Conflict of Interest:}

There is no conflict of interest to be declared.

Authors' contributions:

All authors contributed to this project and article equally. All authors read and approved the final manuscript.

\section{References:}

1) Donaldson MS, Corrigan JM, Kohn LT. To err is human: building a safer health system. National Academies Press. 2000. PMID: 25077248.

2) The Leapfrog Group Hospital Patient Safety Survey. Washington, DC: Leapfrog Group; 2004.

3) Hook J, Cusack C. Ambulatory computerized provider order entry (CPOE): findings from the AHRQ Health IT portfolio. Center for information technology leadership. 2008.

4) Rind DM, Safran C, Phillips RS, Wang Q, Calkins DR, Delbanco TL, et al. Effect of computer-based alerts on the treatment and outcomes of hospitalized patients. Archives of Internal Medicine. 1994; 154(13): 1511-7. doi: 10.1001/archinte.1994.00420130107014.

5) King WJ, Paice N, Rangrej J, Forestell GJ, Swartz R. The effect of computerized physician order entry on medication errors and adverse drug events in pediatric inpatients. Pediatrics. 2003; 112(3): 506-9. PMID: 12949274.

6) Bates DW, Boyle DL, Vander Vliet MB, Schneider J, Leape L. Relationship between medication errors and adverse drug events. Journal of general internal medicine. 1995; 10(4): 199-205. PMID: 7790981. 
7) Kaushal R, Bates DW, Landrigan C, McKenna KJ, Clapp MD, Federico F, et al. Medication errors and adverse drug events in pediatric inpatients. JAMA. 2001; 285(16): 2114-20. doi:10.1001/jama.285.16.2114. PMID: 11311101.

8) Chertow GM, Lee J, Kuperman GJ, Burdick E, Horsky J, Seger DL, et al. Guided medication dosing for inpatients with renal insufficiency. JAMA. 2001; 286(22): 2839-44. doi: 10.1001/jama.286.22.2839. PMID: 11735759.

9) Dexter PR, Perkins S, Overhage JM, Maharry K, Kohler RB, McDonald CJ. A computerized reminder system to increase the use of preventive care for hospitalized patients. New England Journal of Medicine. 2001; 345(13): 965-70. doi: 10.1056/NEJMsa010181. PMID: 11575289.

10) Nightingale P, Adu D, Richards N, Peters M. Implementation of rules based computerised bedside prescribing and administration: intervention study. Bmj. 2000; 320(7237): 750-3. PMID: 10720357, PMCID: PMC27317.

11) Garg AX, Adhikari NK, McDonald H, Rosas-Arellano MP, Devereaux P, Beyene J, et al. Effects of computerized clinical decision support systems on practitioner performance and patient outcomes: a systematic review. JAMA. 2005; 293(10): 1223-38. doi: 10.1001/jama.293.10.1223. PMID: 15755945.

12) Teich JM, Merchia PR, Schmiz JL, Kuperman GJ, Spurr CD, Bates DW. Effects of computerized physician order entry on prescribing practices. Archives of internal medicine. 2000; 160(18): 2741-7. doi: 10.1001/archinte.160.18.2741. PMID: 11025783.

13) Bates DW, Kuperman G, Teich JM. Computerized physician order entry and quality of care. Quality Management in Healthcare. 1994; 2(4): 18-27. PMID: 10172133.

14) Bates DW, Kuperman GJ, Rittenberg E, Teich JM, Fiskio J, Ma'luf N, et al. A randomized trial of a computer-based intervention to reduce utilization of redundant laboratory tests. Am J Med. 1999; 106(2): 144-50. doi: 10.1016/S0002-9343(98)00410-0. PMID: 10230742.

15) Bates DW, Teich JM, Lee J, Seger D, Kuperman GJ, Ma'Luf N, et al. The impact of computerized physician order entry on medication error prevention. J Am Med Inform Assoc. 1999; 6(4): 313-21. PMID: 10428004, PMCID: PMC61372.

16) Bobb A, Gleason K, Husch M, Feinglass J, Yarnold PR, Noskin GA. The epidemiology of prescribing errors: the potential impact of computerized prescriber order entry. Archives of internal medicine. 2004; 164(7): 785-92. doi: 10.1001/archinte.164.7.785. PMID: 15078649.

17) Kaushal R, Shojania KG, Bates DW. Effects of computerized physician order entry and clinical decision support systems on medication safety: a systematic review. Archives of internal medicine. 2003; 163(12): 1409-16. doi: 10.1001/archinte.163.12.1409. PMID: 12824090.

18) Del Beccaro MA, Jeffries HE, Eisenberg MA, Harry ED. Computerized provider order entry implementation: no association with increased mortality rates in an intensive care unit. Pediatrics. 2006; 118(1): 290-5. doi: 10.1542/peds.2006-0367. PMID: 16818577.

19) Bates DW, Leape LL, Cullen DJ, Laird N, Petersen LA, Teich JM, et al. Effect of computerized physician order entry and a team intervention on prevention of serious medication errors. JAMA. 1998; 280(15): 1311-6. doi: 10.1001/jama.280.15.1311. PMID: 9794308.

20) Bizovi KE, Beckley BE, McDade MC, Adams AL, Lowe RA, Zechnich AD, et al. The effect of computer - assisted prescription writing on emergency department prescription errors. Academic Emergency Medicine. 2002; 9(11): 1168-75. doi: 10.1197/aemj.9.11.1168. PMID: 12414466.

21) Hunt DL, Haynes RB, Hanna SE, Smith K. Effects of computer-based clinical decision support systems on physician performance and patient outcomes: a systematic review. JAMA. 1998; 280(15): 1339-46. doi: 10.1001/jama.280.15.1339. PMID: 9794315.

22) Banta HD. Embracing or rejecting innovations: clinical diffusion of health care technology. Use and impact of computers in clinical medicine: Springer; 1984: 132-60.

23) Ash JS, Gorman PN, Seshadri V, Hersh WR. Computerized physician order entry in US hospitals: results of a 2002 survey. J Am Med Inform Assoc. 2004; 11(2): 95-9. doi: 10.1197/jamia.M1427. PMID: 14633935, PMCID: PMC353025.

24) Ash JS, Bates DW. Factors and forces affecting EHR system adoption: report of a 2004 ACMI discussion. J Am Med Inform Assoc. 2005; 12(1): 8-12. doi: 10.1197/jamia.M1684. PMID: 15492027, PMCID: PMC543830.

25) Kaushal R, Bates D. Computerized physician order entry (CPOE) with clinical decision support systems (CDSSs). Making health care safer: A critical analysis of patient safety practices. Evidence Report/Technology Assessment.43. 
26) Kennedy E. Efficiency in health care (eHealth) act of 2002 (introduced in Senate). S 2638: Thomas Legislative Information on the Internet. 2002.

27) The Leapfrog Group for Patient Safety. Computer physician order entry (CPOE) factsheet. 2000. Available from: http://www.leapfroggroup.org/.

28) Joan S. Ash, Paul N. Gorman, Veena Seshadri, William R. Hersh; Computerized Physician Order Entry in U.S. Hospitals: Results of a 2002 Survey, Journal of the American Medical Informatics Association, Volume 11, Issue 2, 1 March 2004, Pages 95-99, doi: 10.1197/jamia.M1427

29) DesRoches CM, Charles D, Furukawa MF, Joshi MS, Kralovec P, Mostashari F, et al. Adoption of electronic health records grows rapidly, but fewer than half of US hospitals had at least a basic system in 2012. Health Affairs. 2013; 32(8): 1478-85. doi: 10.1377/hlthaff.2013.0308. PMID: 23840052.

30) Khajouei R, Wierenga P, Hasman A, Jaspers MW. Clinicians satisfaction with CPOE ease of use and effect on clinicians' workflow, efficiency and medication safety. International journal of medical informatics. 2011; 80(5): 297-309. doi: 10.1016/j.ijmedinf.2011.02.009.

31) Zargarzadeh A, Emami M, Hosseini F. Drug-related hospital admissions in a generic pharmaceutical system. Clin Exp Pharmacol Physiol. 2007; 34(5 - 6): 494-8. doi: 10.1111/j.1440-1681.2007.04600.x. PMID: 17439421.

32) Gholami K, Shalviri G. Factors associated with preventability, predictability, and severity of adverse drug reactions. Annals of pharmacotherapy. 1999; 33(2): 236-40. doi: 10.1345/aph.17440. PMID: 10084421.

33) Kazemi A, Ellenius J, Tofighi S, Salehi A, Eghbalian F, Fors UG. CPOE in Iran--a viable prospect? Physicians' opinions on using CPOE in an Iranian teaching hospital. Int J Med Inform. 2009; 78(3): 199207. doi: 10.1016/j.jimedinf.2008.07.004. PMID: 18760960.

34) Rahimi B, Timpka T, Vimarlund V, Uppugunduri S, Svensson M. Organization-wide adoption of computerized provider order entry systems: a study based on diffusion of innovations theory. BMC Med Inform Decis Mak. 2009; 9(1): 52. doi: 10.1186/1472-6947-9-52. PMID: 20043843, PMCID: PMC2809050.

35) Ehteshami A, Saghaeiannejad S, Tavakoli N, Sadeghi F, Shirzad V, Kasaei M. Computerized provider order entry system: Solution to improve patient safety. International Journal of Health System and Disaster Management. 2013; 1(3): 180-3. doi: 10.4103/2347-9019.129182.

36) Radley DC, Wasserman MR, Olsho LE, Shoemaker SJ, Spranca MD, Bradshaw B. Reduction in medication errors in hospitals due to adoption of computerized provider order entry systems. J Am Med Inform Assoc. 2013; 20(3): 470-6. doi: 10.1136/amiajnl-2012-001241. PMID: 23425440, PMCID: PMC3628057.

37) Reckmann MH, Westbrook JI, Koh Y, Lo C, Day RO. Does computerized provider order entry reduce prescribing errors for hospital inpatients? A systematic review. J Am Med Inform Assoc. 2009; 16(5): 61323. doi: 10.1197/jamia.M3050. PMID: 19567798, PMCID: PMC2744711.

38) Leung AA, Keohane C, Amato M, Simon SR, Coffey M, Kaufman N, et al. Impact of vendor computerized physician order entry in community hospitals. J Gen Intern Med. 2012; 27(7): 801-7. doi: 10.1007/s11606012-1987-7. PMID: 22271271, PMCID: PMC3378729.

39) Riedmann D, Jung M, Hackl WO, Stühlinger W, van der Sijs H, Ammenwerth E. Development of a context model to prioritize drug safety alerts in CPOE systems. BMC medical informatics and decision making. 2011; 11(1): 35. doi: 10.1186/1472-6947-11-35. PMID: 21612623. PMCID: PMC3127742.

40) Campbell EM, Sittig DF, Guappone KP, Dykstra RH, Ash JS. Overdependence on technology: an unintended adverse consequence of computerized provider order entry. AMIA Annu Symp Proc. 2007: 948. PMID: 18693805, PMCID: PMC2710605.

41) Campbell EM, Sittig DF, Ash JS, Guappone KP, Dykstra RH. Types of unintended consequences related to computerized provider order entry. J Am Med Inform Assoc. 2006; 13(5): 547-56. doi: 10.1197/jamia.M2042. PMID: 16799128, PMCID: PMC1561794. 